\title{
Multi-actor modelling for MILP energy systems optimisation: application to collective self-consumption
}

\author{
Lou Morriet $^{1,2}$, Gilles Debizet ${ }^{2}$, Frederic Wurtz $^{1}$ \\ ${ }^{1}$ Univ. Grenoble Alpes, CNRS, Grenoble INP*, G2Elab, F-38000 Grenoble, France \\ ${ }^{2}$ Univ. Grenoble Alpes, CNRS, Sciences Po Grenoble**, Pacte, 38000 Grenoble, France
}

\begin{abstract}
The shape of an energy project depends on the available technologies but also on stakeholders' decisions although most energy-support-decision tools only focus on technical issues. This article aims to propose a multi-actor modelling based on stakeholders' objectives and constraints and to apply it on the optimisation model generation tool OMEGAlpes. This modelling aims to help stakeholders to formalise their constraints and objectives and to negotiate them in a multi- stakeholders design process. Two types of stakeholders involved in urban renewable energy project have been highlighted: operators and infrastructure regulators. This modelling has been applied to a simplified collective selfconsumption project.
\end{abstract}

\section{Introduction}

Cities are consuming more than half of the global primary energy use and energy-related $\mathrm{CO} 2$ emissions (IPCC 2014). The availability to produce or recover local energy is nowadays changing the energy system from centralised to decentralised production and from finite fossil-stock sources to variable renewable-flow sources as depicted by Bulkeley, Castan-Broto and Maasen (2010). Thereby, consumption and production are gathered in the same place but energy projects must be designed at the district scale taking into account this new paradigm. This paper seeks to contribute to it.

This new paradigm and the complexity of energy projects creates a need for decision support tools in order to help decision makers to formulate the problem, find solutions and attest their availability, and discuss them between stakeholders. Actually, the number of energy tools drastically increased over the past 20 years (Connolly et al. 2010; Lopion et al. 2018). However, these tools focus only on technical or techno-economic issues.

An energy system should be considered as sociotechnical, as it is comprise technical (material selection, available technology...) and social (social practice, political and legal institutions...) dimensions (Akrich 1989). On the same idea, Jaccard (2005) defines an energy system as a "combined processes of acquiring and using energy in a given society or economy" which highlights the role of the society.

Thereby, social sciences and interdisciplinary researches related to energy have highlighted the role of the stakeholders in the definition of energy system project
(Soshinskaya et al. 2014; Debizet 2016; Hinker et al. 2017). Soshinskaya et al. (2014) highlight stakeholders as one of the barriers of urban renewable energy development due to their self-interest and a lack of trust. Considering support decision tools, Hinker et al. (2017) define the "socio-technical optimality gap" in order to highlight the difference between the best computed techno-economic solution and the actual system implementation. Finally, Debizet et al. (2016) points out that future urban energy systems may shape differently depending on who is the main decision-maker, that deal with or enlist other stakeholders.

Working at district scale, new stakeholders like citizen energy cooperatives, flexible industries, or prosumers consumers with the new ability to produce its own energy - should be taken into account in the modelling. In fact, the local scale enable them to have more influence on the future system. That is why the stakeholders should be considered as part of the decision-making considering their constraints and objectives. Thereby, we will aim to consider district energy projects as multi-stakeholders energy projects.

Working in multi-stakeholders projects, taking into account many and various constraints and objectives, and in pre-study phases, often entail an empty space of solutions. In fact, ignoring the other stakeholders' constraints and objectives, all stakeholders will often begin proposing strong constraints and objectives that he or she will gradually have to negotiate in order to identify available solutions. The former assessments lead us to focus on helping the stakeholders on two points: first, help them understand the impact of their requirements and objectives and secondly help them discuss and coordinate on available solutions. This contribution is thus dedicated to "problem setting" issues more than "problem solving" issues.

Li et al. (2015) state that actors and more precisely actor heterogeneity should be explicitly modelled in support decision tools. Six tools investigating power demand and/or supply while modelling explicitly actors' heterogeneity are identified in the article. Those tools use agent-based model and dynamic simulation for modelling actors' behaviours. However, we do not aim to model actors' behaviours but rather actors' objectives and constraints in order to enable the stakeholders to negotiate them in a multi-stakeholder design process. This may lead 
to create a more holistic model to reduce the sociotechnical optimality gap defined by Hinker et al. (2017).

This modelling needs to be linked with an energy- projectmodelling tool. Working at the district scale on a prestudy phase entail numerous decision variables, which orient ourselves towards optimisation tools. And more precisely towards Mixed-Integer Linear Programming (MILP), considering continuous and discrete variables, as done in other district optimisation research (Bollinger 2017). However, taking into consideration multistakeholders decisions, the tool should make it possible to easily adapt the energy-project model as well as the actors' constraints and objectives. Thus, optimisation tool dedicated to energy project models generation may be appropriate to test the formulation by searching for interesting solutions.

The papers presents a multi-actor modelling for districtscale energy projects involving various stakeholders. The multi-actor modelling mainly focuses on stakeholders' constraints and objectives. We aim to define a multi-actor modelling for energy project modelling optimisation tools in order to help the multi-stakeholders "problem setting" process. A second section presents a simple and pedagogical use case, based on the multi-actor modelling, on a collective self-consumption project involving a supplier and a prosumer.

\section{Methods}

\section{From the stakeholder definition of district energy projects...}

First, we will propose a definition of the stakeholders involved on district energy project and its modelling as an actor. To do so, we based our work on sociotechnical and interdisciplinary researches. We also based some of our hypothesis on interviews carried out by social sciences researchers.

As mentioned before an energy system should be considered as sociotechnical and thus encompass the whole of energy systems with the technical issues and the associated stakeholders. We consider a stakeholder of a district energy project as a decision-maker or a set of decision-makers with the availability to have a consistent influence on the final solution of the project. The stakeholders' influences can be modelled as constraints and objectives. We define a constraint as a link (in the form of an equation) that reduces the field of possible and possibilities of the energy system. And an objective as an orientation ( $\min$ or max) of a variable tending to move the calculated convergence point within the solution space.

Numerous stakeholders could be considered for modelling (Weijermars et al. 2012; Debizet 2016; Hinker et al. 2017; Li 2017). Hinker et al. (2017) highlight that stakeholders which are considered for the modelling are mainly selected by the modeller and largely depends on the scientific discipline of the modeller. Consequently, we aim to highlight, and then model, a large ensemble of stakeholders even if it may be incomplete due to the variety of urban configurations. We will focus the actor definition on actors' action regarding the energy exchanges, as the modelling should be linked to an energy-modelling tool.

- Consumer: he consumes energy for his own usages

- $\quad$ Producer: he produces energy in order to meet at least part of the consumption of the local energy project.

- Prosumer: firstly a consumer, he becomes a prosumer if he is able to produce energy for his own usages or other actors' energy use interconnected through the energy project.

- Network operator: he ensures the network functioning and development. He mainly ensures the equilibrium between the production and the consumption, leaning on laws for the acceptance of new producers and consumers on the network.

- Supplier and Aggregator: often outside of the local scale, they link the district system or consumers/producers located in the district with the rest of the energy network.

- Regulator: he fixes rules and procedures regarding the relations between the prior actors. Regulations concern network and/or resources.

This whole of actors can be divided in two categories: operators and regulators. In fact, social science literature (North 1990; Moss 2009), distinguishes regulating actors from operating actors. The first ones lay down rules and procedures that the second ones have to respect.

The first category includes actors who are directly operating the energy units. This category will be called "operator actors". The consumer, producer, prosumer, network operator, supplier and aggregator belong to this category. The concept of "area of responsibility" may be used to define the whole of the energy units operated by an actor. Debizet et al. (2016) define it as "a group of physical elements collecting, converting, and/or supplying energy, built (or operated) by the same decision-maker". They also named it "socio-energy node" because the whole urban energy system results of an assemblage of socio-energy nodes.

It can be noted that this first category gathers two kinds of actors: the ones fully on the energy project and the ones at the interface between the former ones and the rest of the whole urban energy system, including different networks and buildings. However, we will not make any difference in our modelling.

The second category gathers the actors who do not operate the energy units but are influencing the final decision with network and resource regulation. This category will be called "network and resources regulation actors". In contrary to the former ones, these actors do not operate a socio-energy node but can affect the whole of the energy elements. This action, being able to inhibited actions, is defined in Hinker et al. article (2017) as "compulsion".

Due to the weak or indirect impact, we decided not to take into account other stakeholders like: multinational organizations, science and technology communities, 
private sector, non-governmental organizations, media, general public like social networks (Weijermars et al. 2012), etc.

\section{... to the MILP multi-actor modelling}

As mentioned before, the modelling should be adapted to MILP optimisation modelling in order to help in designing and operate urban renewable energy projects. MILP problems can be formulated as follow:

$$
\text { Minimise } c^{T} x+d^{T} y
$$

Subject to: $\mathrm{Ax}+\mathrm{By} \leq \mathrm{b}$

$$
\mathrm{x} \min \leq \mathrm{x} \leq \mathrm{x} \max , \mathrm{y} \in\{0,1\}^{\mathrm{m}}
$$

With:

$c \in I^{n}, d \in I^{m}, b \in I^{p}$ data vectors

$x \in \operatorname{IR}^{\mathrm{n}}, \mathrm{y} \in\{0,1\}^{\mathrm{m}}$ variables vectors

$\mathrm{xmin} \in \mathrm{IR}^{\mathrm{n}}$, $\mathrm{xmax} \in \mathrm{IR}^{\mathrm{n}}$ low and up bounds vectors

$\mathrm{A} \in \mathrm{IR}^{\mathrm{pxn}}$ and $\mathrm{B} \in \mathrm{IR}^{\mathrm{pxm}}$ matrixes to define the variable constraints

This formulation and show how a MILP problem is defined by objectives and constraints. Stakeholders' objectives and constraints, which seem essential in the energy project definitions, can thus easily be modelled in a MILP modelling. Figure 1 highlights how a constraint can drastically reduce the decision space, to maybe an empty solution space, and thus the importance to be able to negotiate some constraints. The modelling process leads us to focus firstly on quantitative ones.

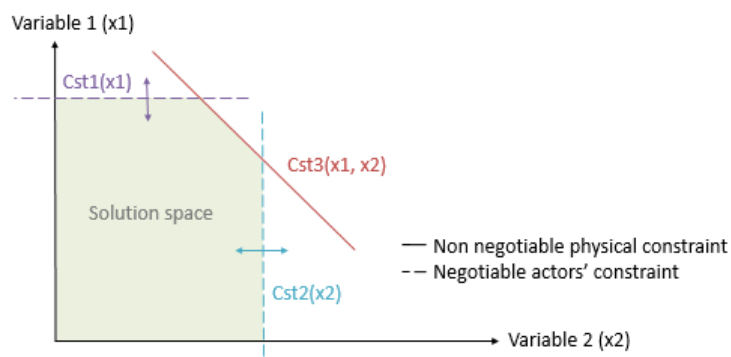

Figure 1: Actors' constraint impact on the solution space.

Object-oriented programming (OOP) and associated programing languages formalism like UML have been developed by computer sciences in order to help in developing comprehensive modelling. OOP focuses on developing codes and models based on "object", which is defined as "a model of real essence in a programming system" (Berdonosov, Zhivotova, et Sycheva 2015). Considering the object-oriented paradigm, actors should and will be modelled as objects. In order to help to model the actor's heterogeneity, various class of actors are predefined in the model. These classes are presented below and are summarized with their attributes and methods in the actor UML class diagram of Figure 44.

The first main class of our modelling is the Actor class. An actor is defined by its availability to have constraints and objectives. Methods are thus available to add or remove specific constraints and objectives of an actor into the energy project model. Actors' objectives can focus on energy autonomy, economic or environmental subjects. It consists on minimising or maximising a quantity like

energy, costs or a $\mathrm{CO} 2$ emission rate for instance. A weight can be added to an objective in order to be able to give more importance to one or several objectives regarding the others. A graphical representation of an actor is proposed on Figure 22.

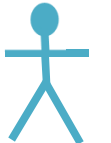

Actor

\section{weight_1 1 objective 1 \\ weight_2 $*$ objective 2 \\ - Constraint 1 \\ - Constraint 2}

Figure 2: Actor representation.

The two kinds of actor highlighted previously, namely "operator actors" and "network and resources regulation actors", can be modelled as parent classes inheriting from the Actor class. Thereby, they are divided in two subpackages: operator_actors and regulator_actors, which will be presented below.

The operator_actors sub-package includes an OperatorActor class, which enable to define the area of responsibility. A representation is proposed in Figure 33. The area of responsibility can be represented by a rectangle framing the actor's energy units. This rectangle may need to be opened if the actor's area of responsibility goes beyond the scope of the project with regard to energy.

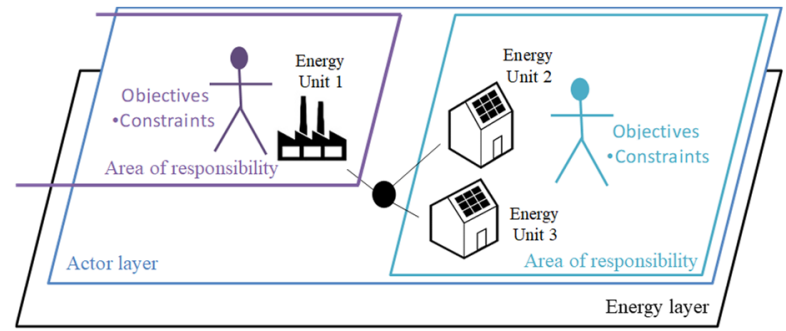

Figure 3: Actor's area of responsibility representation.

It is modelled with the following characteristics:

- The energy units should be the same type of the actor. For instance if the actor is a consumer, the available units for its area of responsibility should only be a consumption unit.

- The objectives and constraints can only be applied to the units of the area of responsibility. Otherwise, an error shows up. If no unit is specified while adding an objective or a constraint to the model, the objective or constraint is applied to the whole area of responsibility of the actor.

Two types of actor classes directly inherit from the OperatorActor class: Consumer class and Producer class. Appropriate constraints and objectives are pre-modelled. The Prosumer class inherits from the Consumer and the Producer classes. Prosumer class becomes particularly interesting as its area of responsibility gathers consumption and production energy units. Indeed, these objectives can make it possible to adapt one unit design or operation to another.

Few objectives $(\mathrm{Obj})$ are specifically dedicated to prosumers: optimizing the match between the production and the consumption, the self-production rate or the self- 
consumption rate. Self-production rate is defined as the self-produced consumption divided by the total consumption (CRE 2017). Self-consumption rate is defined as the self-consumed production divided by the total local production (CRE 2017). To tackle the intermittence issue of renewable energies, these optimisations are calculated at each step t. Matching consumption with production corresponds to minimise the absolute value of the difference between the local consumption and the total production as presented in equation (2).

\section{Obj: Minimise $\left(\sum_{t}(\mid\right.$ local production[t] - total consumption $[\mathrm{t}] \mid$ )}

Maximise the selfconsumption and selfproduction rates while keeping the formulation linear, requires to minimise the difference between the self-produced consumption and the total consumption (equation (3)) or to minimise the difference between the self-consumed production and the total production (equation(4)).

Obj: Minimise $\left(\sum_{t}(\mid\right.$ selfproduced consumption $[t]-(3)$ total consumption[t]l)

Obj: Minimise $\left(\sum_{t}(\mid\right.$ selfconsumed production[t] -

$$
\text { total production }[\mathrm{t}] \mid)
$$

A Supplier class is also added to the model. As a supplier may collect over energy produced locally while providing energy. That is why, the Supplier class needs to inherit from Consumer and Producer classes. Prosumers and suppliers are both producing and consuming or collecting energy; thus they are gathered in the same module: producer_consumer_actors.

Network operator and aggregator are not modelled for the moment but will be modelled later for further needs.
The regulator_actors sub-package enables one to model regulations acting on network (economical, values...) and resources. A RegulatorActor class have been modelled to distinguish these actors from operator actors. Two main kinds of authorities, which are not developed yet, have been identified and thus modelled as classes inheriting from the RegulatorActor class: LocalAuthorities and StateAuthorities.

\section{Actor modelling in a MILP optimisation tool dedicated to energy project modelling}

Focusing on helping decision-makers to define the whole of the available solutions, we decided to base our work on an optimisation tool. Focusing on improving decision makers' understanding of their objective and constraints influence and enabling them to discuss about various study case, we decided to work with a model generation tool. Focusing on facilitating the model and tool access to the stakeholders, we decided to work on an open source tool.

Two main tools are currently available under the previous conditions : oemof - Open Energy Modelling Framework - (Hilpert et al. 2018) and OMEGAlpes - Optimisation ModEls Generation As Linear Programming for Energy Systems - (Pajot et al. submitted to BS2019). The former actor modelling has been developed on OMEGAlpes, which is developed locally.

OMEGAlpes aims to be developed in layers. The first layer enables to model an energy model but only focusing on the technical elements. A specific economical layer will be developed later in order to separate technical and economical issues. What we aim is to propose a new layer: the multi-actor modelling layer, enabling to consider actors' quantitative objectives and constraints as illustrated in Figure 3.

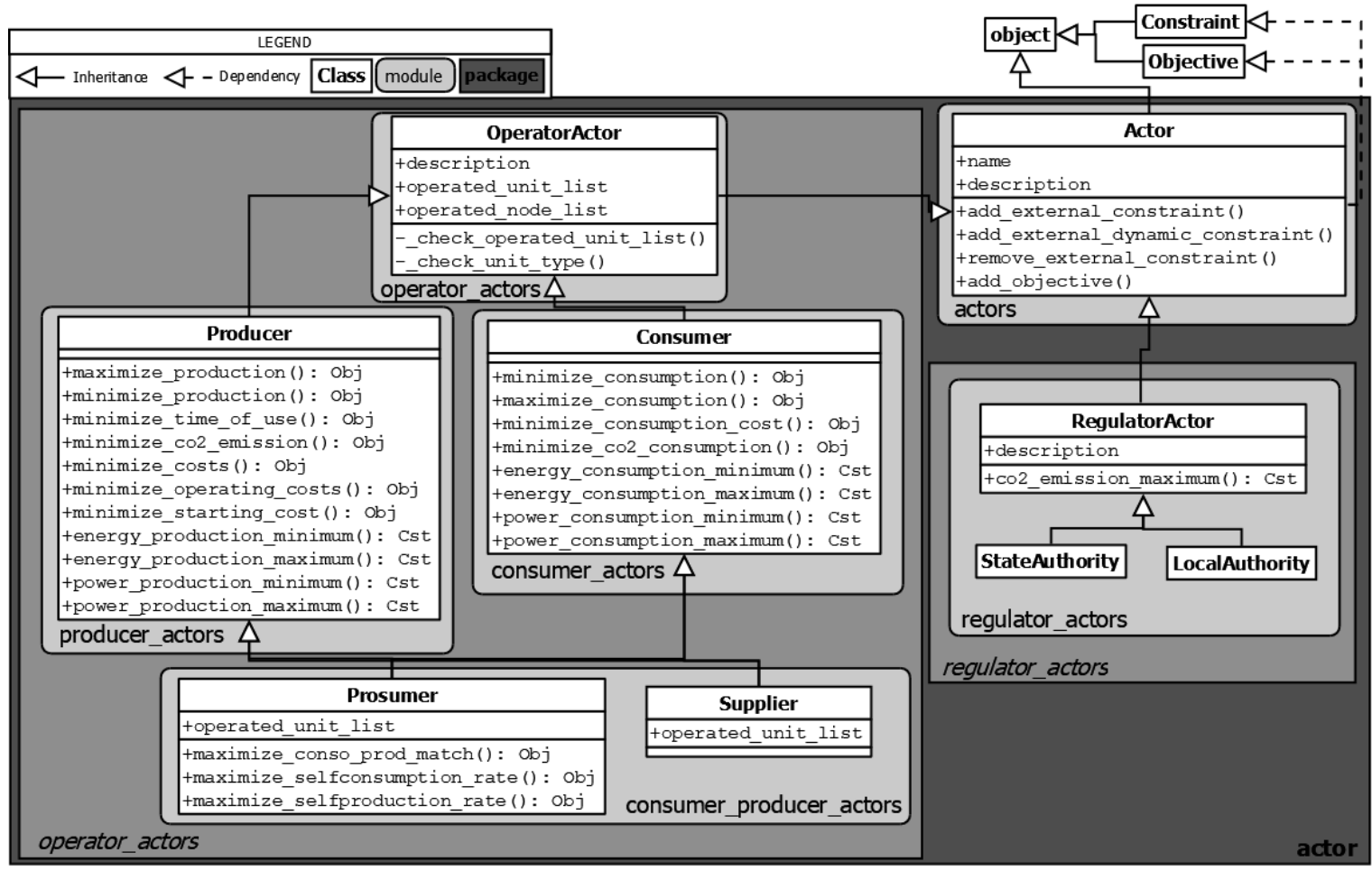

Figure 4: Actor class diagram. 
These objectives and constraints need then to be discussed and negotiated between the stakeholders, especially during the "problem setting" phase that can be identified in collaborative preliminary design of project.

OMEGAlpes (Pajot et al. submitted to BS2019) is based on object-oriented programming, developed with Python, and provides basic energy units such as Production, Consumption, Conversion or Storage units in order to facilitate the energy system modelling with its physical constraints. The energy units should be connected through an energy node in order to insure the consumptionproduction equilibrium at each step. The energy units have also predefined operational options, associated objectives and physical constraints. For instance, a physical constraint may be to require a certain delay between the shutdown and restart of the production power plant. An objective may be to minimise the consumption of a dwelling. However, in our point of view, this kind of objective should be linked to actors for a better understanding of the energy project and stakeholders' impact. Furthermore, this proposition offers a bigger panel of modelling possibilities as the prosumer modelling detailed before highlights.

In order to link the Actor class with the optimisation problem definition, the Actor class inherits from the elementary Unit class. Furthermore, the Actor class relies also on two optimisation elements: the Objective and the Constraint classes. OMEGAlpes proposes two kinds of constraints: non-negotiable constraints, mainly dedicated to the energy units, and negotiable constraints, mainly dedicated to the actors. This modelling consideration enables to easily remove negotiable constraints if there is no solutions to the problem for instance, and thus to determine if the physical requirements are not too restrictive.

Finally, the definition of the actor's area of responsibility for the operator actors is done during the actor's initialisation. The link between an operator actor and its energy units to define its area of responsibility is based on an "operator" attributes of the energy units.

\section{Application}

This section aims to illustrate the actor modelling proposed above on a simple and educational use case based on a collective self-consumption project. Working at pre-studies and on the problem setting phases, we aim to highlight the need of identifying stakeholders' requirements and model them as constraints in order to assess their impact. The modelling is thus one contribution to the stakeholders' negotiation.

\section{Collective self-consumption French regulatory frame}

In France, the collective self-consumption act enables prosumers to share their electricity production between various consumers connected to the public network. (Décret $n^{\circ}$ 2017-676 2017). This act aims to develop renewable energy production in France. It is currently developed at district scale in cities and by definition involves various stakeholders in the project.

Collective self-consumption implies the creation of a legal entity composed of one or more producers and one or more final consumers. The legal entity has to fix a "repartition key" which defines the rate of the local electricity production, e.g. produced by photovoltaic (PV) panels of prosumers, assigned to the different consumers. Although the electricity physically goes to the closest consumption point, the key repartition theoretically distinguishes electricity supplied by PV prosumer and by (exogenous) supplier as represented in Figure 55.

\section{Optimisation concerns}

Only aiming to show the potentiality of the actor modelling, we only consider an inter-building scale in this use case although OMEGAlpes could consider bigger scales. The optimisation consist in identifying an accurate size for the PV panels, and thus the accurate number of panels, considering stakeholders' needs. As represented in Figure 55, two potential actors are considered in this case study:

- a supplier, which supplies the energy to the consumer and collect the surplus of the PV. It is modelled from the Supplier class.

- a prosumer, modelled from the Prosumer class, who gathers a set of consumers and a PV producer. Its area of responsibility includes two houses with fixed consumption load and a certain amount of PV panels to determine. These PV production capability is modelled as a fixed production profile with the possibility to have a variable amount of it.

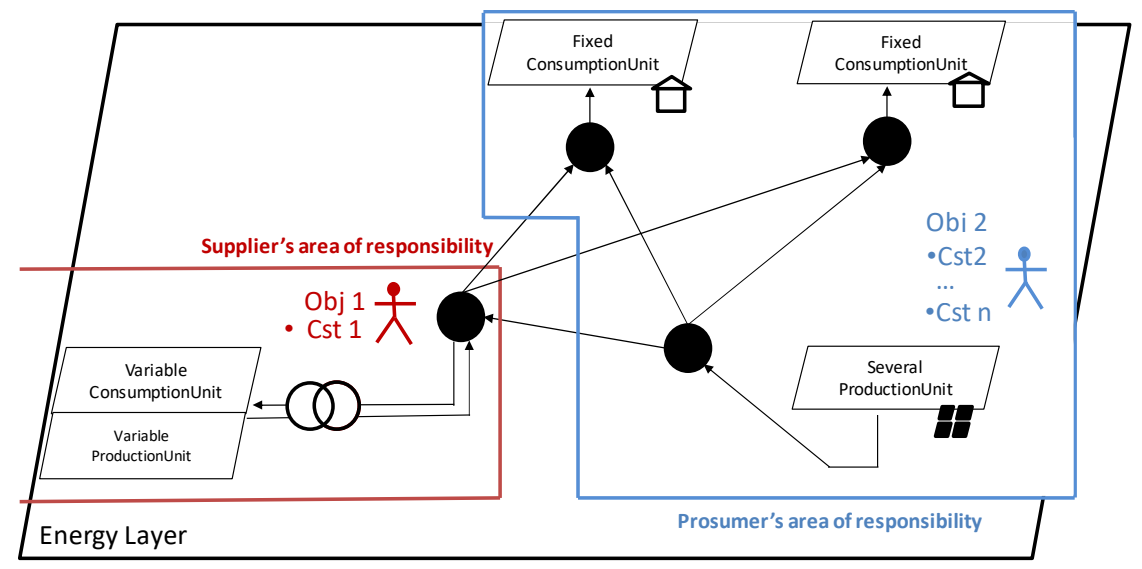

Figure 5: Simple collective self-consumption study case representation. 
Table 1: Summary of the case study data.

\begin{tabular}{|c|c|c|c|c|}
\hline Stakeholders & Energy unit name & OMEGAlpes Energy Unit & Variables & Associated data \\
\hline \multirow{2}{*}{ Supplier } & supplier_consumption & VariableConsumptionUnit & S_prod[t] & \\
\cline { 2 - 5 } & supplier_production & VariableProductionUnit & s_conso[t] & \\
\hline \multirow{3}{*}{ Prosumer } & dwelling_consumption_1 & FixedConsumptionUnit & d_1[t] & $\begin{array}{c}15 / 09 / 20186 \mathrm{kVA} \text { consumption } \\
\text { curve - 50 kWh/day (Enedis 2016) }\end{array}$ \\
\cline { 2 - 5 } & dwelling_consumption_2 & FixedConsumtpionUnit & d_2[t] & $\begin{array}{c}15 / 09 / 20186 \mathrm{kVA} \text { consumption } \\
\text { curve - 50 kWh/day (Enedis 2016) }\end{array}$ \\
\cline { 2 - 5 } & local_pv_production & SeveralProductionUnit & $\begin{array}{c}\text { pv[t],pv_nb, } \\
\text { pv_u[t] }\end{array}$ & 250Wc PV panel production curve \\
\hline
\end{tabular}

\section{Use case based model}

The code for the study case model can be found on the OMEGAlpes-Example / article case study repository; the file is untitled article_2019_BS_multiactor_modelling.py: https://gricad-gitlab.univ-grenoblealpes.fr/omegalpes/omegalpes-examples.

The first step is to create a time for the use case and then an empty model including the time. The time step will be half-hour as required for establishing a repartition key. Although the repartition key should be determined for a whole month, we will work on a day period for a simpler understanding.

The second step is to create the energy layer, which data are summarized in Table 1. The consumption units are two houses untitled dwelling_consumption_l and dwelling_consumption_2. Both are modelled as FixedConsumptionUnit which means that the consumption curves are predefined. The consumption profiles are estimated on a national residential consumption profile with a low tension and subscription power under $6 \mathrm{kVA}$ proposed by Enedis for the $15^{\text {th }}$ of September 2018 (Enedis 2016). The average electricity consumption considered is $50 \mathrm{kWh}$ /day for each dwelling. The photovoltaic (PV) production, called local_pv_production, is based on a predefined production curve for $250 \mathrm{Wc}$ PV panel. However, the number of PV panels is a variable, which may be optimised. Thus the PV production is modelled as SeveralProductionUnit. The data profiles can be download into OMEGAlpes from files. The supplier energy units are modelled as infinite power network with the VariableConsumptionUnit - called supplier_consumption - and VariableProductionUnit called supplier_production - classes. Nodes are then created to enable the electricity exchanges and insure the production consumption equilibrium at each step.

The third step is to create the actor layer. Both actors are operators and thus described with their area of responsibility. The Supplier operates the supplier_production and the supplier_consumption units. The Prosumer operates the dwelling_consumption_1, the $d w e l l i n g \_c o n s u m p t i o n \_2$, and the local_pv_production units. It lasts to add the actors' objectives and constraints, which will be detailed on the following parts.

Study one: example of a too many constrained energy project leading to an empty solution space

For this first study, each actor has its own constraints (Cst) that will be added on the model.
The supplier does not want to collect the surplus of the PV panel. Thus, the following constraint is added to model the fact that no local energy can be sent to the network:

$$
\text { Cst: } \quad s \_c o n s o[t]==0
$$

The prosumer has three constraints and one objective. First, they want to install at least one PV panel (see equation (6)). However, there is a limited place on the roof to install the PV panels. The place available corresponds to a number of $40 \mathrm{PV}$ panel pv_nb (see equation (7)). Finally, the prosumer wants to consume only local production while the PV is producing energy, which means while the binary variable pv_u is equal to 1 (see equation (8)). Thus, the following constraints are added:

$$
\begin{aligned}
\text { Cst: } & p v \_n b>=1 \\
\text { Cst: } & p v \_n b<=40
\end{aligned}
$$

Cst: $d \_1[t] * p v \_u[t]+d \_2[t] * p v \_u[t]<=p v[t]$ (8) The prosumer has the objective to maximise the matching between le local PV production and the dwelling consumptions. Thus, the objective to maximise the matching between the PV production and the dwellings consumption in added to the prosumer (see equation (2)): Finally, the model should be optimised and solved. However, the optimisation of the model is infeasible. This means that the decision space is empty. In fact, integrating multiple stakeholders in energy project decision may lead to have empty space of solution due to too many constraints asked by the stakeholders However, before trying to negotiate the stakeholders' constraints, the actors constraints may be removed to insure that the technical optimisation problem is not too constrained. If checked, stakeholders' constraints should be discussed and so, stakeholders should understand which constraints should be relaxed. This is one aim of this tool. Different possibilities exist, but it is possible to remove some constraints, remove one actor's constraints, test with different constraints or transform the constraints into the objective. The last solution will be tested in the following part.

\section{Study two: various optimised number of PV panels considering actors' decisions}

The supplier constraint is thus changed into the objective of minimising the consumption.

The constraint on the maximum number of PV panel (7) is kept, while the constraint (6) on a minimum number of PV panel and the one about the only local production (8) are removed. The prosumer objective is kept. 
Once solved, the solution calculated proposes the installation of $34 \mathrm{PV}$ panels of $250 \mathrm{Wc}$. Considering that there is a need for the stakeholders to understand the scope of solutions available we will plot the pareto curve which enables one to represent the compromises between 2 contradictory objectives as in Figure 66. Both objectives are thus weighted with the coefficient $\alpha$ such as $0 \leq \alpha \leq 1$ :

Obj: $\alpha *$ supplier.minimise_consumption +

$(1-\alpha)^{*}$ prosumer. maximise_conso_prod_match

The accurate number of PV panels varies between 0 and $37 \mathrm{PV}$ pannels. Considering these objectives it is unuseful to install more than $37 \mathrm{PV}$ panels because local production is becoming too high in relation to consumption. After $37 \mathrm{PV}$ panels, both objectives stop being in opposition. The Gaussian shape of the photovoltaic production curve explains the impossibility of drastically reducing the difference between the local production and the dwelling consumptions.

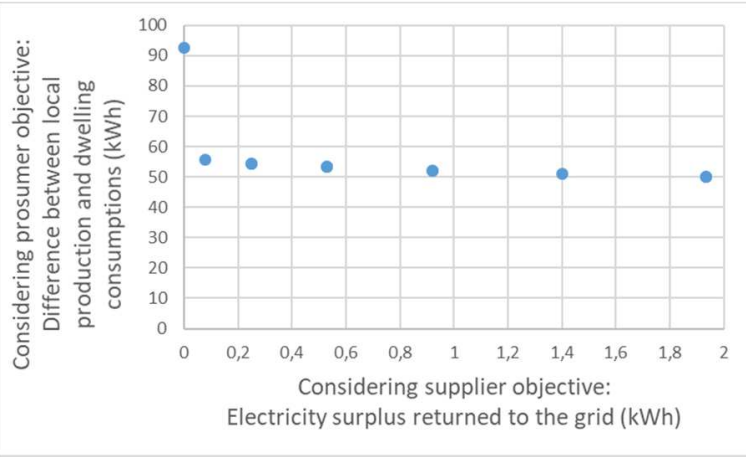

Figure 6: Pareto frontier for the PV panel sizing.

\section{Discussion about the actor modelling}

Urban energy project should be considered as sociotechnical issues and therefore take into account both technical issues and social influence.

In this article, social influence is reduced to stakeholders' requirements and objectives in the modelling although various modelling, like agent-based, could be considered (Li, Trutnevyte, et Strachan 2015; Hinker et al. 2017). This choice is mainly based on two considerations: the fact that stakeholders' constraints and objectives have a significant impact on the final energy system solution and the fact that the stakeholders will have to discuss their needs and requirements on a multi-stakeholder negotiation process and not within the tool. The negotiation may however be based on the modelling and the outputs. This is why we do not seek to take into account stakeholders' behaviour in our modelling but only their requirements and objectives. In addition, one should keep in mind that modelling will always be too restrictive considering the real project. However, it may help to give a better understanding.

Decision support modelling tools lead us to focus firstly on quantitative constraints and objectives. Actually, we firstly focused on classical energy, economic and environmental analysis. However, other researches are also investigating semi-quantitative modelling (Döll, Döll, et Bots 2013) which is a research track for later.

\section{Conclusion and perspectives}

The energy-production decentralisation and the use of local sources changed the decision scale for energy projects towards local decision involving new stakeholders. Social sciences and interdisciplinary researches highlighted the stakeholders' influence on the final shape of an energy project but few support decision tools include this dimension.

This paper aims to present a multi-actor modelling for Mixed-Integer Linear Programming (MILP) optimisation integrating stakeholders' requirements and objectives, as social sciences and interdisciplinary researches highlighted their influence on the final shape of an energy project. This contribution is more dedicated to help "problem setting" issues than "problem solving" issues. This modelling aims to help stakeholders to define and formalise their objectives and constraints, understand their impacts on the energy project and more generally help them discuss and coordinate on available solutions.

An actor is defined on the model as a set of constraints and objectives based on MILP modelling. As a first step in multi-actor modelling, we propose to distinguish and model two types of actors: "operator actors", actors with an area of responsibility including the energy units they operates, and "network and resources regulation actors". Consumer, Producer and Prosumer are among the operator actors and are pre-modelled with objectives and constraints. The actors' predefined objectives and constraints should be supplemented with analysis of district energy projects, mainly carried out by social researchers. Other actor models may also be required.

This multi-actor modelling aims to help in complex and multi-stakeholder local energy projects such as collective self-consumption. It is an emerging trend in several European countries and an effective reality in some developing countries. Repartition keys, rules and social norms are key points for the development of this kind of project. Other complex energy project like local intermittent production with electrical storage and/or thermal storage and conversion may be addressed with this modelling, which should now be tested on real energy projects.

An educational study case, based on collective selfconsumption, is presented in the paper. It shows the potential of highlighting stakeholders' constraints and objectives in modelling and optimisation. In fact, too many constraints may reduce the solution space to an empty one. Highlighting the constraints may help the stakeholders to negotiate them in order to agree on an energy system. In addition, highlighting the objectives may enable to understand what would influence the multiactor energy project.

Next research tracks would consist in developing collaborative modelling that allows the use of private data while preserving their confidentiality. Or, to enable the use of various stakeholder tools with secure model and/or data exchange, as well as decentralized solving and negotiation. 


\section{Acknowledgement}

This work has been partially supported by the CDP EcoSESA receiving fund from the French National Research Agency in the framework of the "Investissements d'avenir" program (ANR-15-IDEX-02) and by the ADEME the French Agency for Environment and Energy Management with the RETHINE project.

\section{References}

Akrich, M. (1989). La construction d'un système sociotechnique. Anthropologie et sociétés 13(2), 31-54.

Berdonosov, V., Alena Z., \& Tatiana S. (2015). TRIZ Evolution of the Object-Oriented Programming Languages. Procedia Engineering, TRIZ and Knowledge-Based Innovation in Science and Industry, 131(janvier), 333-42.

Bollinger, L.A. (2017). Impact of electricity price policies on optimal district energy system design. Proceedings from BSO2017: Building Simulation Conference. San Francisco, 7-9 August 2017.

Bulkeley, H., Castan-Broto V., \& Anne Maassen. (2010). Governing Urban Low Carbon Transitions. In Cities and Low Carbon Transitions, 1st Edition. Routledge. New York (USA)

Connolly, D., Lund, H., Mathiesen, B.V., \& Leahy M. (2010). A review of computer tools for analysing the integration of renewable energy into various energy systems. Applied Energy 87(4), 1059-82.

CRE (2017). Elements de réflexion - Les enjeux associés au développement de l'autoconsommation. http://www.smartgrids-

cre.fr/media/documents/evenements/Autoconsommat ion_elements_reflexion.pdf.

Debizet, G. (2016). Scénarios de transition énergétique en ville: acteurs, régulations, technologies. La Documentation française. Paris (France).

Debizet, G., Tabourdeau, A., Gauthier, C., \& Menanteau, P. (2016). Spatial processes in urban energy transitions: considering an assemblage of SocioEnergetic Nodes. Journal of Cleaner Production, Special Volume: Transitions to Sustainable Consumption and Production in Cities, 134(octobre), 330-41.

Décret $n^{\circ}$ 2017-676 du 28 avril 2017 relatif à l'autoconsommation d'électricité et modifiant les articles D. 314-15 et D. 314-23 à D. 314-25 du code de l'énergie. 2017. https://www.legifrance.gouv.fr/eli/decret/2017/4/28/ DEVR1707686D/jo/texte.

Döll, C., Döll, P., \& Bots, P. (2013). Semi-quantitative actor-based modelling as a tool to assess the drivers of change and physical variables in participatory integrated assessments. Environmental Modelling \& Software 46(août), 21-32.

Enedis. (2016). Coefficients des profils. https://www.enedis.fr/coefficients-des-profils.
Hilpert, S., Kaldemeyer, C., Krien, U., Günther, S., Wingenbach, C., \& Plessmann., G. (2018). The Open Energy Modelling Framework (oemof) - A new approach to facilitate open science in energy system modelling. Energy Strategy Reviews 22 (novembre), 16-25.

Hinker, J., Hemkendreis, C., Drewing, E., März, S., Hidalgo Rodríguez, D.I., \& Myrzik, J.M.A. (2017). A novel conceptual model facilitating the derivation of agent-based models for analyzing socio-technical optimality gaps in the energy domain. Energy 137(octobre), 1219-30.

IPCC (2014). Climate Change 2014: Synthesis Report. Contribution of Working Groups I, II and III to the Fifth Assessment Report of the Intergovernmental Panel on Climate Change [Core Writing Team, R.K. Pachauri and L.A. Meyer (Eds.)]. Geneva (Switzerland).

Jaccard, M.K. (2005). Sustainable fossil fuels: the unusual suspect in the quest for clean and enduring energy. Cambridge University Press. Cambridge (UK).

Li, F.G.N. (2017). Actors behaving badly: Exploring the modelling of non-optimal behaviour in energy transitions. Energy Strategy Reviews 15(mars), 57-71.

Li, F.G. N., Trutnevyte, E., \& Strachan, N. (2015). A review of socio-technical energy transition (STET) models. Technological Forecasting and Social Change 100(novembre), 290-305.

Lopion, P., Markewitz, P., Robinius, M., \& Stolten, D. (2018). A review of current challenges and trends in energy systems modeling. Renewable and Sustainable Energy Reviews 96(novembre), 156-66.

Moss, T. (2009). Intermediaries and the Governance of Sociotechnical Networks in Transition. Environment and Planning A 41 (6), 1480-95.

North, D.C. (1990). Institutions, Institutional Change and Economic Performance. Cambridge University Press. Cambridge (UK).

Pajot et al. (submitted to BS2019). OMEGAlpes: An Optimization Modeler as an Efficient Tool for Design and Operation for City Energy Stakeholders and Decision Makers.

Soshinskaya, M., Crijns-Graus, W.H.J., Guerrero, J.M., \& Vasquez, J.C. (2014). Microgrids: Experiences, barriers and success factors. Renewable and Sustainable Energy Reviews 40(décembre), 659-72.

Weijermars, R., Taylor, P., Bahn, O., Ranjan Das, S., \& Wei, Y.M. (2012). Review of models and actors in energy mix optimization - can leader visions and decisions align with optimum model strategies for our future energy systems? Energy Strategy Reviews, Energy System Models \& Natural Gas Strategies 1 (1), 5-18 